\title{
"Exhorto a la obediencia del rey". La postura de los franciscanos del Colegio Real y Pontificio de Celaya ante la Independencia
}

\author{
Ma. Elena Ruiz Marín*
}

a postura de las órdenes mendicantes ante la revolución de in-
dependencia aún da mucho de qué hablar. ${ }^{1} \mathrm{Al}$ respecto, la car-
ta franciscana que más adelante presentamos nos parece
ejemplar por sus connotaciones políticas y religiosas. Para su lectura
contextualizada son necesarios algunos señalamientos introductorios.

NotA INTRODUCTORIA

El hecho político que dio pie a la misiva que presentamos, fue la declaración que hizo el rey Fernando VII la noche del 7 de marzo de 1820, sobre su intención de jurar la Constitución de Cádiz de 1812; acto que realizó dos días después.

La Constitución de Cádiz de 1812 fue producto de la reorganización de un gobierno en crisis, debido a la invasión francesa llevada a cabo por Napoleón Bonaparte en el año de 1808, y a la abdicación de Carlos IV y de su hijo Fernando VII, rey de España, a favor de José Bonaparte. Ambos soberanos mantuvieron su apoyo a la Iglesia al poner como única condición para su renuncia al trono que la religión católica siguiera siendo el credo oficial de la monarquía, ya que en la historia de su conformación como reino la religión fue un factor de cohesión entre sus componentes. David Brading señala a

\footnotetext{
*Virginia Marín Rubio in memoriam, mi madre, saltarello_14@yahoo.com.mx

${ }^{1}$ A este respecto puede consultarse: Eric Van Young, La otra rebelión: la lucha por la Independencia de México, 1810-1821, México, Fondo de Cultura Económica, 2006.
} 
este respecto que en aquella Constitución no hubo declaración alguna que favoreciera los derechos del hombre como en su contraparte francesa, pero dejó establecido que "la religión de la Nación española es y será perpetuamente la católica, apostólica y romana, única verdadera" ${ }^{2}$ Cabe señalar que cuatro siglos antes los reyes católicos, por medio de una política centralizadora, aprovecharon las reformas de la Iglesia para asegurar la unidad de las diferentes Coronas buscando primero la unidad religiosa de los súbditos, consiguiendo así la progresiva unificación política. ${ }^{3}$

En la Constitución de Cádiz de 1812 se observa la influencia de los ideales liberales franceses expresados en el acotamiento del absolutismo mediante la división de poderes. En este sentido, el legislativo correspondió a las Cortes reservándole un amplio poder de decisión para hacer contrapeso al monarca; y el poder ejecutivo recayó en un rey con un papel acotado pese a ser el responsable del orden público y la seguridad nacional.

En la Constitución también "se establecieron los principios de soberanía nacional", ${ }^{4}$ y se permitió la libertad de prensa y de expresión. Se declaró "una igualdad muy relativa entre los derechos de los peninsulares y los americanos". 5

Las Cortes suprimieron "todos los derechos y las jurisdicciones feudales que seguían existiendo"6 en España, abolieron la Inquisición en el año de 1813 y "prohibieron a las comunidades religiosas pedir dinero para reestablecer sus casas tras la salida de las tropas francesas", 7 además de negarles la admisión de novicios. Con estas medidas se puede observar una abierta toma de distancia del gobierno con respecto a la Iglesia.

En el mes de marzo de 1814, Fernando VII volvió a España luego de su estadía en Francia. A su regreso se encontró con la realidad

${ }^{2}$ David Brading, Apogeo y derrumbe del imperio español, México, Clío, 1996, 53.

${ }^{3}$ Francisco Martín Hernández, Historia de la Iglesia, volúmen II: La Iglesia en la época moderna, Madrid, Ediciones Palabra, 2000, 84.

${ }^{4}$ Elsa Gracida y Esperanza Fujigaki, "La revolución de independencia” en Enrique Semo, coord., México, un pueblo en la historia, México, Alianza Editorial, 1992, 138.

${ }^{5}$ Gracida y Fujigaki, 1992, 138.

${ }^{6}$ David Brading, 1996, 53.

${ }^{7}$ David Brading, 1996, 53. 
de las Cortes y la Constitución; apoyado por 69 diputados conservadores -y al menos dos obispos- aprobó el Manifiesto de los Persas, con el que consumó un golpe absolutista. Para el mes de mayo del mismo año, el rey disolvió las Cortes y anuló e invalidó todos sus actos; con este hecho restauró la monarquía absoluta, restableciendo a la Inquisición y persiguiendo y encarcelando a los liberales que habían apoyado las reformas constitucionales.

Los posteriores seis años fueron de reacción política y de represión en contra de los liberales españoles. El país estaba devastado por los efectos de la invasión francesa y los recursos disponibles para el Estado fueron cada vez más escasos porque la monarquía lidiaba con los levantamientos independentistas en América.

El primero de enero de 1820, el coronel Rafael de Riego dio inicio a la rebelión liberal, pronunciándose contra el absolutismo. Pronto fue apoyado por las unidades del ejército expedicionario que estaban listas para zarpar a América, por guarniciones militares y por comandantes del ejército que no accedieron a reprimir las revueltas que se iban sumando con los meses en varias ciudades importantes del reino. Finalmente, la presión de la multitud obligó a Fernando VII a la declaración del día 7 de marzo de 1820.

\section{Nueva España}

Mientras tanto, las ideas liberales ya se habían permeado en algunos sectores de la sociedad colonial. Se pueden observar en los primeros diputados americanos, como Miguel Ramos Arizpe, que participó en los debates de 1811 para diseñar la futura Constitución de Cádiz; en ellos defendió las ideas sobre la soberanía popular, la división de poderes, la igualdad de derechos, la igualdad de representación para las provincias ultramarinas y el derecho a tener mayor autonomía en el gobierno colonial. ${ }^{8}$

A lo largo de la década de la guerra de independencia se observan fuertes altibajos en la lucha militar contra el gobierno colonial, pero también la maduración de las ideas liberales en la búsqueda de la

${ }^{8}$ Gracida y Fujigaki, 1992,136. 
formación de la nación. Esto se puede ver a través de la generación de diversos documentos expedidos por los insurgentes, por ejemplo, en los Elementos Constitucionales de 1812 redactados por Ignacio López Rayón; en la Declaración de Independencia de 1813, debida a la pluma de Carlos Bustamante; en la Exposición de motivos sobre las causas de la independencia, redactadas por Andrés Quintana Roo; y desde luego en la Constitución de Apatzingan de 1814 defendida por José María Morelos.

Cuando Fernando VII jura la Constitución de Cádiz en el año de 1820, el virrey Juan Ruiz de Apodaca y la Real Audiencia se vieron obligados a hacer lo mismo, generando con esto una gran inquietud en los grupos conservadores. Restablecida la Constitución liberal y las Cortes, la Iglesia se vio de nuevo afectada por la supresión del fuero eclesiástico, la expulsión de la Compañía de Jesús, por la desaparición de todas las órdenes monásticas, por la venta de los bienes eclesiásticos y la reducción de los diezmos. ${ }^{9}$ En este contexto novohispano fue leída la misiva que da pie a este trabajo.

\section{LA DESCRIPCIÓN}

Esta carta ${ }^{10}$ inédita forma parte del acervo del Archivo Histórico Provincial, de la Provincia Franciscana de San Pedro y San Pablo de Michoacán, ubicado en la ciudad de Celaya Gto. En el índice aparece con el título de "Exhorto a la obediencia del rey"; el documento es una carta escrita por fray Cirilo Alameda y Brea, ministro general de la Orden de Menores y predicador del rey, expedida en el convento de San Francisco de Madrid y refrendada por el secretario general con fecha del $1^{\circ}$ de abril de 1820. La misiva está dirigida a todos los religiosos, prelados y súbditos sujetos a la obediencia franciscana, con la orden de que estas "letras patentes" circulen a las provincias y colegios de América para su conocimiento y cumplimiento.

${ }^{9}$ Luis Villoro, "La revolución de independencia", en Historia General de México, México, El Colegio de México, 2004, 518.

${ }^{10}$ Sección Gobierno, serie Patentes, caja 14, núm. 145, fecha 1820. 
Para entender el orden en que aparecen los nombres de los frailes, al inicio del documento se seńala que fray Cirilo Alameda fue el autor de la epístola, misma que escribió el $1^{\circ}$ abril; luego debió ser enviada, a fray Juan Buenaventura, entonces comisario general de la Orden en las Indias; y finalmente debió remitirse a todas las autoridades religiosas franciscanas, entre ellas a fray Manuel Agustín Gutiérrez, en este caso segundo destinatario de la carta y autoridad del Colegio Real y Pontificio de la Purísima Concepción de Celaya y de la Provincia en donde iba a ser leída. La misiva fue recibida el día 15 de agosto y leída el día 16 del mismo mes.

El Colegio Real y Pontificio de la Purísima Concepción de Celaya era por entonces un centro educativo de gran relevancia regional. Surgió por iniciativa de Pedro Núńez de la Roja, que fue benefactor y fundador, y por Gaspar de Almanza, que tuvo a cargo su administración. El 15 de octubre de 1624 el papa Urbano VIII dictó un Breve por el que quedó establecido el Colegio Real, le concedió privilegios, libertades y prerrogativas del mismo tipo del que disponían los demás colegios de la misma Orden.

La apertura de cursos se llevó a cabo en el año de 1637, y se impartían materias como gramática, arte, teología y lenguas, entre otras. Había áreas de teología, filosofía, retórica, gramática y cánones. ${ }^{11} \mathrm{El}$ papel que desempeñó el Colegio fue el de un centro educativo al que llegaban frailes de otros conventos para incrementar y perfeccionar su formación de religiosos; cabe mencionar que el Colegio sólo recibía a españoles y criollos. Posteriormente, en el año de 1725, el virrey Juan de Acuña solicitó que el Colegio tuviera privilegios de Real Universidad, a fin de que estudiantes seglares pudieran cursar estudios ahí.

En suma, el Colegio Real fue desde su fundación un centro de concurrencia y mayormente de formación de religiosos, un centro de intercambio de experiencias, de inquietudes y de aprendizaje intelectual.

${ }^{11}$ Rafael García Pérez, Colegio de la Purísima Concepción de Celaya: origen y evolución 1617-1767, Tesis de licenciatura en Historia de la Universidad de Guanajuato, 2006. 


\section{ElEMENTOS PARA EL ANÁLISIS}

Los primeros años del siglo XIx fueron difíciles por los cambios y las nuevas ideas, fue una época de transición del colonialismo a una nueva nación. En este sentido, la carta que nos ocupa resulta trascendente, pero no sólo por la referencia a las profundas tensiones políticas del momento y al esfuerzo por evitar que más religiosos se sumaran a un movimiento insurgente en el que se destacaron desde el inicio, sino también por el notable ejercicio de retórica que representa. En la epístola, el ministro general de la orden franciscana intenta compatibilizar las leyes terrenales, que incluso afectan a la Iglesia, con las leyes divinas que en su lógica trascienden tiempos históricos.

El mensaje de fray Cirilo Alameda gira en torno a tres ideas principales: la lealtad, las leyes civiles versus leyes divinas y la exaltación de la obediencia y del orden franciscano. Su mensaje inicia con una reafirmación de lo que debe de ser la digna conducta religiosa franciscana, enseguida hace una amonestación y un llamado a la lealtad recordándoles que deben obediencia a las autoridades constituidas, que deben conservar el orden y dar ejemplo de adhesión al gobierno. Se trata de un llamado a observar una tradición histórica iniciada por san Pablo, una civilidad fundada sobre bases religiosas. Sin embargo, ante este seńalamiento es claro inferir que una parte de los religiosos seguían simpatizando con el movimiento independentista. A continuación les insta a no equivocarse, a no dejarse seducir por los acontecimientos.

La lealtad y el esfuerzo retórico por hacer compatibilizar las leyes civiles con las leyes divinas están presentes en todo el documento como a continuación se menciona. Les recuerda que el rey es el protector de la Iglesia católica (como se sugirió en párrafos anteriores) y Padre de los Regulares, que se le deben favores y que ha jurado la Constitución de Cádiz. Luego, en un discurso con tonalidad nacional los llama hijos de una Patria que no los desconoce; y enseguida, en lo que parece una paradoja, el discurso se convierte en una alocución en torno a Dios, a leyes trascendentes en el que manda a dar al César lo que es del César, y a Dios lo que es de Dios. 
A continuación señala la vida de los franciscanos como modelo de la vida cristiana y los ubica como ciudadanos obedientes de las leyes de Dios, del monarca y de la constitución. En esta parte el ministro general ya asume una obediencia no sólo a las leyes eternas sino a leyes terrenales que se entienden justas.

En esta parte fray Cirilo hace una exaltación de la obediencia y del orden franciscano. Señala que los franciscanos nunca alteraron la paz ni actuaron en contra de lo que convenía a los pueblos en el orden civil, su voz y comportamiento es de la religión y de la palabra de Dios en todos los países. Luego les hace una exhortación a seguir como buenos españoles y cristianos, leales a Roma. Su posición como religiosos franciscanos debe mantenerse sobre la línea de comportamiento trazada por la conducta de sus antecesores, como ellos mismos siguieron la conducta de san Francisco. Huellas del pasado que deben marcar la conducta del presente. Por lo mismo indica que no escuchen de los fieles otras palabras que las de edificación como orden, respeto y obediencia a las leyes de la Constitución, que es base sólida de la sociedad y sobre el cual se levanta el reino de España. Se observa aquí el notable esfuerzo retórico por compatibilizar la obediencia a las leyes terrenales y temporales con las leyes de Dios.

En ese esfuerzo, invita a sus frailes a que actúen como consejeros de los fieles en lo terrenal, que aconsejen que se obedezca al rey, pero que también le hagan entender a los fieles cuales son los derechos de los ciudadanos. Aquí se observa de nuevo la noción de justicia y de derecho para el provecho individual y común, una noción cívica dentro de lo religioso, siempre bajo un orden jerárquico.

El siguiente mensaje insertado a la carta de fray Cirilo Alameda, ministro general de la orden, es el de fray Juan Buenaventura, comisario general de Indias. En él hace un exhorto a la paz, unión y obediencia a las autoridades y a la Constitución. Se percibe que es un llamado a los religiosos franciscanos que estén o puedan estar simpatizando con el movimiento insurgente en la Nueva Espańa.

Finalmente está incluído otro exhorto, esta vez de parte del ministro provincial y rector del Colegio Real, fray Manuel Agustín Gutiérrez, en el que llama a sus religiosos a que no se equivoquen y 
a que no se arriesguen. Subrayando la frase del ministro general en que indica que los días de gloria en curso son también de seducción y riesgos, les señala que la Constitución es sabia, justa y religiosa, que une a todos los espańoles, y que su quebrantamiento conducirá a mayores desgracias. Estas palabras pueden comprenderse como un llamado a sus frailes a que no se involucren en la insurgencia, que acepten el nuevo orden constitucional.

Las tensiones señaladas en este discurso, el ejercicio de lógica y persuasión, y la manera en que se presenta, permiten interpretar que las autoridades franciscanas trataban de hacer compatibles las leyes de comportamiento espiritual con las ciudadanas. De la misma manera, se puede interpretar que en el contexto de la Constitución jurada por Fernando VII, las órdenes mendicantes trataban de asegurar cierta protección pese al perfil antieclesial (no anticatólico) de la misma.

A continuación se presenta la transcripción de la carta. ${ }^{12}$

\section{Documento}

Fray Manuel Agustín Gutiérrez, de la Regular Observancia de nuestro seráfico padre San Francisco. Lector jubilado, ex definidor, Ministro Provincial de la de los gloriosos apóstoles San Pedro y San Pablo de Michoacán, rector del Colegio Real y Pontificio de la Purísima Concepción de Celaya y siervo: A todos los religiosos, así prelados como súbditos, de esta nuestra sobre dicha Provincia salud y paz en nuestro Señor Jesucristo y toda consolación en el Espíritu Santo.

Hacemos saber a vuestras paternidades, reverendas y consejeros que en la tarde de ayer quince del corriente, hemos recibido en dicho nuestro Colegio y Provincia, el correo ordinario las letras patentes de nuestro padre reverendísimo Comisario general que son a la letra del tenor siguiente:

\footnotetext{
${ }^{12}$ Las frases que aparecen entre estos signos = aparecen subrayadas en el documento original.
} 
Fray Juan Buenaventura Bestard,,$^{13}$ doctor y maestro en artes, predicador apostólico, padre de la Provincia de Mallorca, teólogo de la Majestad Católica en su Junta por la Inmaculada Concepción, ${ }^{14}$ Comisario general del Orden de nuestro seráfico padre San Francisco en Indias y siervo:

A todos los religiosos, prelados y súbditos, sujetos a nuestra obediencia, salud y paz en nuestro Señor Jesucristo. Nuestro excelentísimo y reverendísimo padre ministro general, con oficio de 3 de este, nos ha remitido unas letras patentes, con orden de que las circulásemos a nuestras provincias y Colegios de América, para su inteligencia y cumplimiento; y son como siguen:

Fray Cirilo Alameda y Brea, doctor en sagrada teología de la Universidad de Zaragoza, predicador del rey, su teólogo en la Junta para la Inmaculada Concepción, grande de Espańa de primera clase, Ministro General, Comisario visitador y reformador apostólico de toda la orden de Menores de nuestro seráfico padre San Francisco, y siervo en el Señor:

A nuestros muy amados en Jesucristo, religiosos, así prelados como súbditos de nuestra religión seráfica en esta familia cismontana, existentes bajo nuestra obediencia, salud y plenitud de consolación en el Espíritu Santo.

Aunque satisfecho de la digna religiosa conducta que habeis observado en todos tiempos, podría reparar gozoso, y asegurar ahora que no manchariais el buen nombre que se debe a la religión seráfica; aunque después de haberme conocido casi todos los religiosos de la península, oído mis exhortaciones, y obedecido mis mandatos acerca

${ }^{13}$ Fray Juan Buenaventura Bestard, era originario de Palma de Mallorca, llegó en el año de 1787 a la Nueva España y murió en el año de 1831. Fundó y fue guardián del Colegio y Convento Apostólico de San José de Gracia en Orizaba, Veracruz. Fue el último comisario general de las Provincias y Colegios Franciscanos de las Indias. Datos tomados de: David Carbajal López, "Pública utilidad o causa pública: la utilidad de los conventos de la Provincia de Veracruz, 1786-1834”, en: Anuario de estudios americanos, 65, julio-diciembre, Sevilla, 2008, 151-175.

${ }^{14}$ La Junta fue establecida por Real Decreto de Felipe IV el 21 de abril de 1652 . El objetivo era que tanto prelados como teólogos estudiaran todo lo relativo a la defensa de la Inmaculada Concepción. Para ahondar en el tema, véase: P. Juan Meseguer Fernández (o.F.M.), "La Real Junta de la Inmaculada Concepción (1616-1817/20)”, en Archivo Ibero-Americano (AIA) Segunda época, año XV, julio-diciembre 1955, núm. 59-60. 
del modo de comportaros en negocios del siglo; seais solo para esto maestros y consejeros de las virtudes, aunque mis prevenciones sobre la instrucción sólida que debeis tener los que, elegidos por la misericordia de Dios para cooperadores del ministerio apostólico, mostrando las fuentes de donde habeis de beber la pura y sana doctrina, con la cual fecundeis luego el campo del Señor, sembrais también el grano puro, cuidando de su cultivo, separando la cizańa, y recogiendo la mies evangélica con solicitud, no fingida caridad.

Aunque en 13 del último Marzo os dije con la premura del momento cual era vuestro deber para que se respetara el nombre justo que se debe a los Institutos Regulares; no admireís, amados hijos míos que vuelva a amonestar reiterando el mandato de obedecer a las autoridades constituidas, de conservar el orden, y de dar ejemplos de adhesión a los principios del gobierno. El apóstol san Pablo hizo este mismo encargo a su discípulo Tito, para que enseńara a los nuevos fieles cual era su primer deber civil donde quiera que se hallasen: Admone illos, le escribio, admone illos, Principibus et potestatibus subditos esse, dicto obedire ad omne opus bonum paratos esse. ${ }^{15}$ Obligación es de mi ministerio pastoral haceros este importante recuerdo en días, que si son de gloria, de admiración y de memoria sempiterna, lo son también de seducción, de equivocaciones monstruosas y de riesgos.

El rey Fernando el Grande, el monarca de dos mundos, el protector de la Iglesia católica, el padre de los Regulares, a quien debo y debeís tantos, tan señalados y tan provechosos favores; el rey de las Españas Fernando VII, amigo y padre de sus pueblos, ha unido la voluntad de todos en la célebre, inolvidable, venturosa noche del 7 de marzo. Declaró su majestad que juraría la Constitución de la monarquía, sancionada en Cádiz en 1812, la juró en efecto, y el gozo y el inocente placer, y la confianza, y la fraternidad se siguieron al disgusto; a aquel sombrío disgusto que por momentos nos arrastraba al mayor de los males.

${ }^{15}$ Amonéstalos, le escribió, amonéstalos, sean súbditos Príncipes o potestades, a obedecer y estar preparados para toda obra buena. Traducción: Fray Eduardo López (o.f.M.) Doctor en Historia. 
Súbditos de tan gran monarca, hijos de una patria que ni nos desconoce, ni podrá desconocernos con justicia; discípulos de Jesucristo, que nos manda dar al César lo que es del César, y a Dios lo que es de Dios; miembros distinguidos del imperio sacerdotal, cuyo poder es la beneficencia, la caridad, el amor íntimo a nuestros hermanos de cuyas conciencias debemos cuidar, sin cuidar de sus intereses; contentos por nuestra profesión con lo que nos dieren, demandando limosna de puerta en puerta, como nos manda nuestro seráfico padre San Francisco; hombres de paz, obligados a anunciarla, saludando a todos con tan halagüeña insinuación de la pureza de nuestras intenciones; peregrinos en este mundo, cuyas riquezas, mas, intereses y derechos renunciamos por nuestro querer; religiosos en fin, modelo de los cristianos, ¿Quién ha de aventajarnos en obedecer al monarca, ni en dar a nuestros compatriotas pruebas inequívocas de sumisión a las leyes? ¿Quién observara mejor las leyes constitucionales de la monarquía, que los que vivimos casi desde la cuna sujetos a una constitución que mantiene a los súbditos sus derechos, y me prohíbe a mi todo lo que puede dañarles? Somos, es verdad, el objeto de la crítica más severa; se nos hace injusticia no pocas veces; nos calumnian los que no nos conocen; buscan los defectos de algunos, sin hacer caso de las virtudes de los mas que componen nuestra numerosa familia; oímos que se nos zahiere, y epítetos vergonzosos se sustituyen a los sagrados respetables nombres con que debe apellidársenos; pero; cuan bueno sois, joh Dios mío! ese murmullo se acalla con el grito unísono de los hombres de bien; y bendiciones y loores, y alabanzas justas son la recompensa del cumplimiento de nuestros deberes.

No somos de mejor condición, amados hijos míos, los discípulos que lo fue nuestro divino Maestro. Abrid la historia de las edades que nos precedieron: llenas están sus páginas de esta alternativa, y entre vituperios y alabanzas hemos pasado por medio de los siglos, debiéndonos generaciones incontables el don precioso de su instrucción, de su conversión, y de su civilización en numerosas provincias. El Reino de las Españas, en Europa, Asia, África y América, el Reino de las Espańas canta nuestros triunfos sobre la idolatría, hace justicia a nuestro saber, honrándonos entre el catálogo de sus 
hombres célebres, y recuerda que las ciencias y las artes nos son deudoras de muchos de sus adelantamientos. El pan con que nos alimentamos, regado está con el sudor de nuestro rostro; y es la generosa paga que se nos hace por nuestros desvelos a la cabecera de los enfermos; por nuestra asistencia al confesionario; por nuestra sana doctrina en las cátedras y en el púlpito; por nuestra imparcial conducta en los pueblos; por nuestras peregrinaciones al Nuevo Mundo; por nuestros trabajos, edificación y peligro en la Palestina; por nuestro debido exacto cumplimiento de las leyes.

Obedecimos siempre: jamás los religiosos franciscanos alteraron el orden, perturbaron la paz, cambiaron la opinión, ni contradijeron al voto juicioso, recto y de conveniencia provechosa a los pueblos en el orden civil: nuestra conversación debía ser del cielo; y del cielo ha sido por fortuna en todos los países, sin que defectos particulares, ó extravíos de pocos, minoren nuestra justificación. Tiempos que recuerda la historia con placer hacen nuestra apología: las instituciones públicas fueron defendidas; el dogma se sostuvo con dignidad y millares de sitios, regados con la sangre de nuestros hermanos, dan testimonio de que los frailes menores fueron tan buenos espańoles, como cristianos católicos, apostólico-romanos. Sigamos sus huellas. Paratos esse rogo, precipioque ad omne opus bonum $^{16}$. Estad queridos hijos míos, preparados para la grande obra del bien, y del solo bien real y efectivo. Santificaos, para que santifiqueís a los demás, y no oigan de vosotros los fieles otras palabras que las de edificación: a saber, orden, respeto y obediencia a las leyes fundamentales sancionadas en la Constitución política de la monarquía, bases sólidas de la sociedad; y sobre las cuales ha de levantarse el edificio grandioso del poder y magnificencia del Reino de las Españas.

Si nuestros compatriotas buscasen nuestro consejo, enseñadles que la religión de nuestros padres ha de conservarse por leyes sabias y justas, como la única verdadera, según esta prescrito en la Constitución; enseñadles que la persona del rey es sagrada e inviolable y

${ }^{16} \mathrm{Y}$ mando que estén preparados para toda obra buena. Traducción: Fray Eduardo López (o.F.M.) Doctor en Historia. 
que debemos amar y obedecer a su majestad; haced que entiendan cuáles son los derechos del ciudadano, cuáles los de la Nación, qué pueden los tribunales, quienes son sus jueces, como se averiguan los delitos, y como los castiga la ley para el escarmiento; enseñadles que significa libertad en una sociedad constituída, como se renuncian los derechos, se transmiten al todo, y se retienen, y como esta hermosa unión aconsejada a los hombres por Dios, por la naturaleza, y por la conveniencia individual, es en procomún provecho de todos: Paratos esse ad omne opus bonum ${ }^{17}$. Defensores de la fé, de los misterios de la religión, de los cánones de la Iglesia, de las santas costumbres de los cristianos, predicad el evangelio, y sobre su doctrina sólida reprended los vicios argüid oportuna e importunamente, si se os compeliere, a los necios partidarios de las pasiones y de las puerilidades de este mundo perecedero: dad ejemplos de virtudes; y esa muda, pero irresistible doctrina, de la cual recibimos repetidas instrucciones por nuestro seráfico padre san Francisco, avergonzará al vicio, y derrocará su malhadado poderío. Fieles a Dios, a vuestros próximos, y a vosotros mismos, dad a cada uno cuanto se debe de justicia.

Dadas en este convento de nuestro padre San Francisco de Madrid, rubricados de nuestra mano, selladas con el mayor de nuestro oficio, refrendadas por nuestro secretario general en $1^{\circ}$ de Abril de 1820. Fray Cirilo Alameda, Ministro general.

Por mandado de nuestro excelentísimo y reverendísimo padre Ministro general. Fray Francisco José Soler, Definidor general y secretario general de la Orden.

He aquí, padres y hermanos míos, delineados los pasos que quiere demos nuestro prelado en la grande mudanza del gobierno. El conocimiento práctico que me asiste de vuestra conducta religiosa, el ser sacerdote y ministro del Dios de la paz e hijos del serafín en carne mortal, perfecto modelo de obediencia, hace que descanse tranquilo mi espíritu, prometiéndose el más decidido amor de todos y cada uno de mis muy amados hijos, a la paz y unión fraternal, a la mas ciega obediencia, a las autoridades, a la observancia de la

\footnotetext{
${ }^{17}$ Estén preparados para obra buena. Traducción: Fray Eduardo López (o.F.M.) Doctor en Historia.
} 
Constitución que ha jurado el rey, y ha mandado juremos todos, y a la perfección y santificación propia y de nuestros hermanos. Dadas en este nuestro marto [sic] de Indias de nuestro seráfico padre San Francisco de Madrid, firmadas de nuestra mano, selladas con el mayor de nuestro oficio, y refrendadas por nuestro secretario general a $1^{\circ}$ Abril de 1820 .

Fray Juan Buenaventura Bestard, Comisario general de Indias. Por mandado de su Paternidad reverendísimo Fray Antonio Fran, secretario general de Indias.

Acabaís de oír, reverendos, padres, hermanos e hijos nuestros muy amados, lo que nuestro excelentísimo y reverendísimo padre ministro general nos dice, encarga y ordena por las anteriores letras, que en la substancia, y en los mas de sus puntos peculiares casi en el modo, os tiene ya dicho prevenido y mandado vuestro ministro provincial en las de diez y seis de Junio de este año con respeto a la obligación que tenemos para con las autoridades constituidas, y en orden a la Constitución que hemos jurado y al cumplimiento de los deberes de nuestro ministerio contra los varios enemigos de ella disfrazados o manifiestos; obligación ciertamente que más que en otros tiempos, lo es en los presentes del cargo pastoral, importando $\mathrm{su}=$ recuerdo= en nuestros días acaso más que nunca; porque, como nuestro excelentísimo prelado expresamente nos lo dice en la preinsertas, si ellos =son días de gloria, lo son también de seducción, de equivocaciones monstruosas y de riesgos $=$.

La Constitución es sabia, justa, religiosa, importantísima en el estado actual que es en el que ya la ha puesto nuestro rey desde =la célebre inolvidable y venturosa noche del siete de marzo=, en que con un solo acto de su augusta voluntad =ha unido=, cuanto es de parte del rey, la de todos los espańoles, que debimos estarlo por la puntual observancia y el respeto de aquel código de leyes fundamentales, capaces, si se observan como es justo, de hacer la felicidad de toda la monarquía; y cuyo quebrantamiento no conducirá sino a las mayores desgracias. Sus principales artículos, en cuanto Constitución política, son los cuatro primeros, en que estriban y sobre que ruedan con firmeza todos los que en el mismo orden contiene su excelente colección. Lo son ellos en sí mismos, enten- 
didos y cumplidos a la letra; esto es, sin estorsionarlos a sentidos, que no lo hayan sido ni podido ser de la nación española en sus representantes y su rey.

Si el tiempo y otras atenciones lo permitieren, se ha propuesto vuestro ministro provincial hacer ver algún día tan clara como la luz la legitimidad de ellos, y respectivamente de los demás contenidos en aquella sabia y junta colección: que entretanto os encargamos la observancia mas cumplida de las letras superiores preinsertas, y reencargamos las de todas las demás, que sobre la materia os hemos dirigido y nuevamente os recomendamos por las presentes, firmadas de mi mano y nombre, selladas con el mayor de nuestro oficio, y refrendadas del infrascripto ${ }^{18}$ pro secretario ${ }^{19}$ de provincia; y las cuales se leerán, cumplirán y circularán según estilo y con arreglo al derrotero del pie.

Dadas en este nuestro Convento y Colegio de Universidad de la Purísima Concepción en la ciudad de Celaya a los diez y seis días del mes de Agosto del ańo de mil ochocientos veinte. En entre renglones $[. . .]^{20}$

Fray Manuel Agustín Gutiérrez [rúbrica]

Ministro Provincial

Por mandado de su paternidad muy reverenda

Fray Francisco Yustis [rúbrica]

Pro Secretario

Derrotero.

Ríoverde y Misiones.

\footnotetext{
${ }^{18}$ Lo abajo escrito.

${ }^{19}$ Pro secretario, el que firma y el que suple al secretario.

${ }^{20}$ Palabra ilegible en el original.
} 